\title{
ALLOY 718 FOR OILFIELD APPLICATIONS
}

\author{
J.J. deBarbadillo and S.K. Mannan \\ Special Metals Corporation \\ 3200 Riverside Drive \\ Huntington, WV, 25705
}

Keywords: Alloy 718, Oilfield Equipment, Stress-corrosion Cracking, Microstructure

\begin{abstract}
Alloy 718 (UNS N07718) was developed for use in the aircraft gas turbine engine, but its unique combination of room temperature strength and aqueous corrosion resistance make it a candidate for oilfield fasteners, valves, drill tools and completion equipment. Its popularity stemmed in part from its availability in a wide range of bar sizes from distributors. As oil and gas well environments became more severe, stress corrosion and hydrogen embrittlement failures in production equipment were experienced. This drove the evolution of the chemistry and microstructure that distinguishes today's oilfield grade 718 from aerospace grades. This paper reviews the development of the grade and its applications and describes some of its unique characteristics, testing and manufacturing methods. Consumption of 718 in the oilfield has probably reached its peak. Offshore production from deep sour fields created a demand for stronger, more corrosion resistant alloys has led to the development of new alloys that have begun to erode 718's market share. The last section of the paper describes these new alloys.
\end{abstract}

\section{Introduction}

Eiselstein recalled in his keynote paper to this conference in 1991 that the original goal of his work that led to the development of alloy 718 was a "matrix stiffened alloy" for an application as piping for supercritical steam power plants [1]. The alloy base possessed the attributes of aqueous and high temperature corrosion resistance, weldability and formability needed for that application. The observation that niobium in the range 4.5 to $6.0 \%$ produced an intense agehardening reaction with good high temperature stability led him redirect his focus to creep rupture properties with aircraft gas turbine applications in mind. The alloy 718 patent makes no disclosure regarding the alloy's aqueous corrosion resisting capabilities [2].

It did not take the International Nickel Co. (later Inco) long to recognize that alloy 718 would be useful in ambient or low temperature applications where there was a need for high strength, toughness and moderate resistance to acids and salts. An early Inco product brochure touts the alloy as: "...useful in combating chloride-ion stress corrosion cracking. Chromium imparts an ability to withstand attack by oxidizing media and sulfur compounds. Molybdenum is known to contribute to resistance to pitting in many media" [3]. These alternative uses for alloy 718 in the chemical, marine and oil and gas industries were facilitated by the availability of stock from the expanding use of the alloy in aircraft turbine applications. Initially material having the aircraft specified heat treatment and microstructure was directly applied for non-aero applications.

As the oil and gas industry moved into coastal and then marine locations and drilled deeper wells with higher pressure and higher temperature (HPHT) fluids with corrosive contaminants, they 
discovered that the useful strength of martensitic alloy steels such as AISI 4340 was limited by both hydrogen embrittlement and stress corrosion cracking. Nickel-base alloys such as C-276 (UNS N10276) and 625 (UNS N06625) have exceptional resistance to pitting, crevice corrosion and stress corrosion cracking in chloride environments, but require cold working to achieve the strengths needed for load bearing applications. Use of cold worked alloys is limited to modest cross-sections and components may have non-uniform hardness. Age-hardened alloys such as K500 (UNS N05500) and X-750 (UNS N07750) are used in oilfield equipment but have proven far less versatile than alloy 718. Alloy 718 was first used in the 1970's for fasteners, valve stems, shafts and drill tools, applications that involve little or relatively brief exposure to corrosive conditions. In the early 1980's alloy 718 began to be considered for use in critical well completion equipment such as hangers, packers and sub-surface safety valves. These are critical pressure containing and/or load bearing components that experience long-term exposure to corrosive media. Inevitably service failures began to be experienced. Subsequent failure analyses and laboratory simulation defined the alloy's limitations and led to the development of today's controlled microstructure alloy. The redefined alloy 718 for sour oil-field service employs a unique chemistry, solution treatment, aging cycle and microstructure designed to maximize stress corrosion resistance, while balancing yield strength and fracture toughness.

\section{Oilfield Applications of Alloy 718}

The use of alloy 718 for oil and gas production was reviewed Kolts [4] and Onyewuenyi [5] in the inaugural Alloy 718 Symposium and more recently by Bhavsar [6]. As noted above, the first uses were for high strength fasteners, valve gates, seats, stems, and springs initially in applications where corrosion conditions were modest and failure consequences were limited. In many cases alloy 718 replaced lower strength and more expensive alloys such as K-500 and X750. Later applications included drill tools that are subject to some corrosion/erosion exposure and higher operating temperatures and pressures, but in which exposure was for a limited duration. These include devices such as logging-while-drilling (LWD) and measurement-whiledrilling (MWD) tools in which sophisticated electronic instruments are contained by an alloy tube that must be both strong and non-magnetic.

The application of alloy 718 for well completion equipment that remain in use for many years brought a new dimension to the forefront. Critical down-hole components such as surfacecontrolled subsurface safety valves (shuts off flow at the top of the well), side-pocket mandrels (injects inhibitors), packer and seal assemblies (control and direct flow at the foot of the well into the collection pipe) and hangers (supports the production tubing string at the well head) must be able to withstand continuous operation in high-pressure corrosive fluids. In-service failure of a component of this type could result in the loss of the well and possibly a "blow-out" that could risk an uncontained release of deadly $\mathrm{H}_{2} \mathrm{~S}$. One failure of a hanger on an offshore well in the North Sea reportedly cost the operator hundreds of millions of dollars (see discussion below). The recent blow-out in the Gulf of Mexico, while not initially believed to be a materials related failure, illustrates the magnitude of the potential consequences to the well owner.

Completion equipment components are tubular in shape to fit into the well casing and allow passage of the production fluid. They may be mechanically attached or physically part of the drill string. They can be very complex in design, containing surface controlled hydraulic or electrically actuated devices to regulate or stop flow or inject inhibitors. Components are usually machined into a complex tubular shape from fully heat-treated, solid bar stock of the appropriate size and they may be as much as ten feet in length. In a few cases components are made from 
heavy-wall extruded tubing. Each of the major oil tool manufacturers has its proprietary component designs tailored to function in specific field environments, but they conform to the general configuration. Two examples of completion equipment shown in cutaway view are depicted in Figure 1.
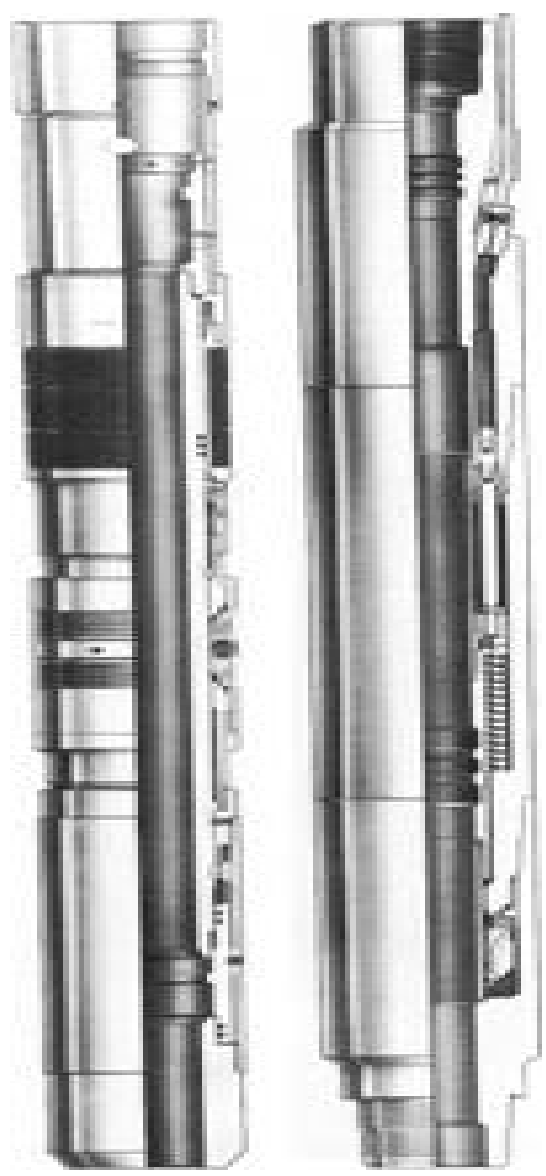

Figure 1. Cutaway drawing of two examples of sub-surface completion equipment. Left: Otis Versa-Trieve production packer used extensively for sand control applications. Right: Otis SP-1 flapper type sub-surface safety valve used to shut off flow from a production tubing string. Otis is a division of Halliburton Energy Systems.

Another type of critical oilfield components that may be made from high strength nickel-base alloy is wellhead distribution equipment. These components reduce pressure through a complex system of valves and combine or distribute the oil and or gas flow. These may be Christmas trees named for their external configuration or master block valve bodies. In the case of offshore wells these devices sit on the ocean floor. They are machined from a block forged from a single ingot that may in some cases weigh as much as $20,000 \mathrm{lb}(9000 \mathrm{~kg})$. A machined Christmas tree internal is shown in Figure 2. 


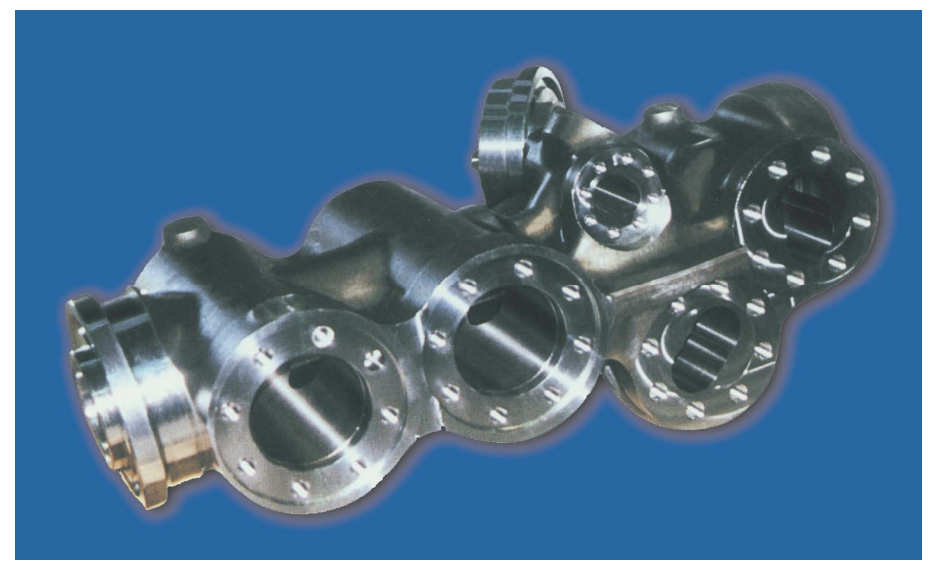

Figure 2. Block gas-well Christmas tree forged and machined from alloy 925. Photograph provided by FMC Petroleum Equipment Company)

\section{Oilfield Corrosion Environments and Testing}

Over the past century oil and gas production has moved from easily accessible shallow and relatively "sweet" reserves to today's deep "sour" reserves, that are frequently offshore and require stronger and more corrosion resistant alloys. In reality there is no typical oilfield environment, each reservoir has its unique chemical combination of $\mathrm{pH}$, chloride, $\mathrm{H}_{2} \mathrm{~S}, \mathrm{CO}_{2}$ and sometimes, free sulfur in addition to mixtures of light and heavy oil, methane, particulates and water. Drilling additives and inhibitors that affect fluid chemistry may also be present. Marine environments that can induce pitting and crevice corrosion in all but the most resistant alloys must also be considered for sea floor, riser and platform equipment.

Standards for the use of alloy 718 under conditions where sulfide stress corrosion cracking and galvanically-induced hydrogen stress cracking may occur are defined by NACE MR0175/ ISO15156-3 [7]. This is an exceedingly complex document that outlines testing procedures as well as ranges of yield strength, hardness, temperature and chemistry conditions where materials can be used. New materials and qualified conditions are accepted by committee ballot only after rigorous review of verifiable test data developed using NACE specified standard test solutions. Testing under galvanic coupling with steel is essential for nickel-base alloys due to the potential for hydrogen embrittlement.

Table I which is adapted from Table A.32 of MR0175 illustrates the range of acceptance limits for use of wrought alloy 718. These levels are intended for guidance only as the individual operator is responsible for qualifying materials to the actual field environment. Note that the acceptable level of $\mathrm{H}_{2} \mathrm{~S}$ decreases with increasing temperature. Alloy 718 can be used when free sulfur is present only below a temperature of $135^{\circ} \mathrm{C}$.

As can be deduced from the conditions of temperature, solution chemistry and pressure, testing for oilfield applications is very specialized and requires use of a high-pressure autoclave and capability of dealing with an accidental release of $\mathrm{H}_{2} \mathrm{~S}$. Only a few commercial testing laboratories are capable of performing these tests. Testing procedures and specimen configurations are defined by the NACE standard TM0177-04 [8]. Two types of environmental test are commonly performed, slow strain rate testing (SSRT) and sustained load tests. 
Table I. NACE MRO175 Test conditions. Specific qualifications may also require galvanic coupling to steel and specific levels of $\mathrm{pH}$ and free sulfur.

\begin{tabular}{|l|l|l|l|l|}
\hline $\begin{array}{l}\text { Max. Temperature } \\
{ }^{\circ} \mathrm{C}\left({ }^{\circ} \mathrm{F}\right)\end{array}$ & $\begin{array}{l}\text { Max. } \mathrm{PP} \mathrm{H}_{2} \mathrm{~S} \\
\mathrm{KPa}(\mathrm{psi})\end{array}$ & $\begin{array}{l}\text { Chloride } \\
\text { Conc. }\end{array}$ & $\mathrm{pH}$ & Sulfur \\
\hline $232(450)$ & $200(30)$ & $*$ & $*$ & No \\
\hline $204(400)$ & $1400(200)$ & $*$ & $*$ & No \\
\hline $199(390)$ & $2300(330)$ & $*$ & $*$ & No \\
\hline $191(375)$ & $2500(360)$ & $*$ & $*$ & No \\
\hline $149(300)$ & $2800(400)$ & $*$ & $*$ & No \\
\hline $135(275)$ & $* *$ & $*$ & $*$ & Yes \\
\hline $\begin{array}{l}* \text { Any combinations of chloride concentration and in situ pH occurring in production } \\
\text { environments are acceptable. } \\
* * \text { Any combinations of hydrogen sulfide, chloride concentration and in situ pH in production } \\
\text { environments are acceptable. }\end{array}$ \\
\hline $\begin{array}{l}\text { Maximum hardness of solution treated and aged material is Rc 40, all other material conditions } \\
\text { maximum hardness is Rc 35. }\end{array}$
\end{tabular}

The SSRT uses a smooth-bar threaded tensile specimen. It is primarily used for screening, characterization and acceptance testing because it is inexpensive and of relatively short duration. Two sets of tests are done, one in air and three in the environment at a constant strain rate of $4 \mathrm{x}$ $10^{-6} / \mathrm{sec}^{-1}$. Test duration is typically about 24 hours. Test criteria are based ratios of time to failure, tensile reduction of area, or elongation in environment and air. A ratio of 0.9 is passing without qualification. If the ratio is between 0.8 and 0.9 ; the fracture surface must be examined by SEM to rate the percentage of inter-granular cracking. The fracture surface must show predominantly ductile fracture mode with no secondary inter-granular cracking. In a more severe version of this test, the sample tested in the environment is coupled galvanically to steel to simulate conditions of hydrogen charging. It should be mentioned that the interpretation of these ratios is based on experience with cold-worked alloys for production tubing. Although the same ratios are applied to age-hardened alloys, these materials tend to have lower values despite their good SCC performance [9]. Consequently, the SSRT is useful in comparing various agehardened alloys with each other, but the raw numbers will not relate to other forms of materials such as cold drawn tubing.

The sustained load testing is more involved, time consuming and costly, but is generally used for qualification of rod materials. Both "C-ring" and multiple-point load test configurations are acceptable, but the former are more commonly used in industry. An example of a C-ring test specimen is shown in Figure 3. A testing regime usually includes multiple samples stressed to $100 \%$ of the yield stress, placed in an autoclave with the required environment and tested for 90days. Failure criteria are based on either complete failure or presence and depth of micro-cracks revealed by a cut and polished section. C-ring test results are difficult to interpret since this is a "go-no go" probabilistic test that does not indicate how close one is to the limit. Multi-point bend tests are more quantitative but are generally conducted for scientific purposes. 


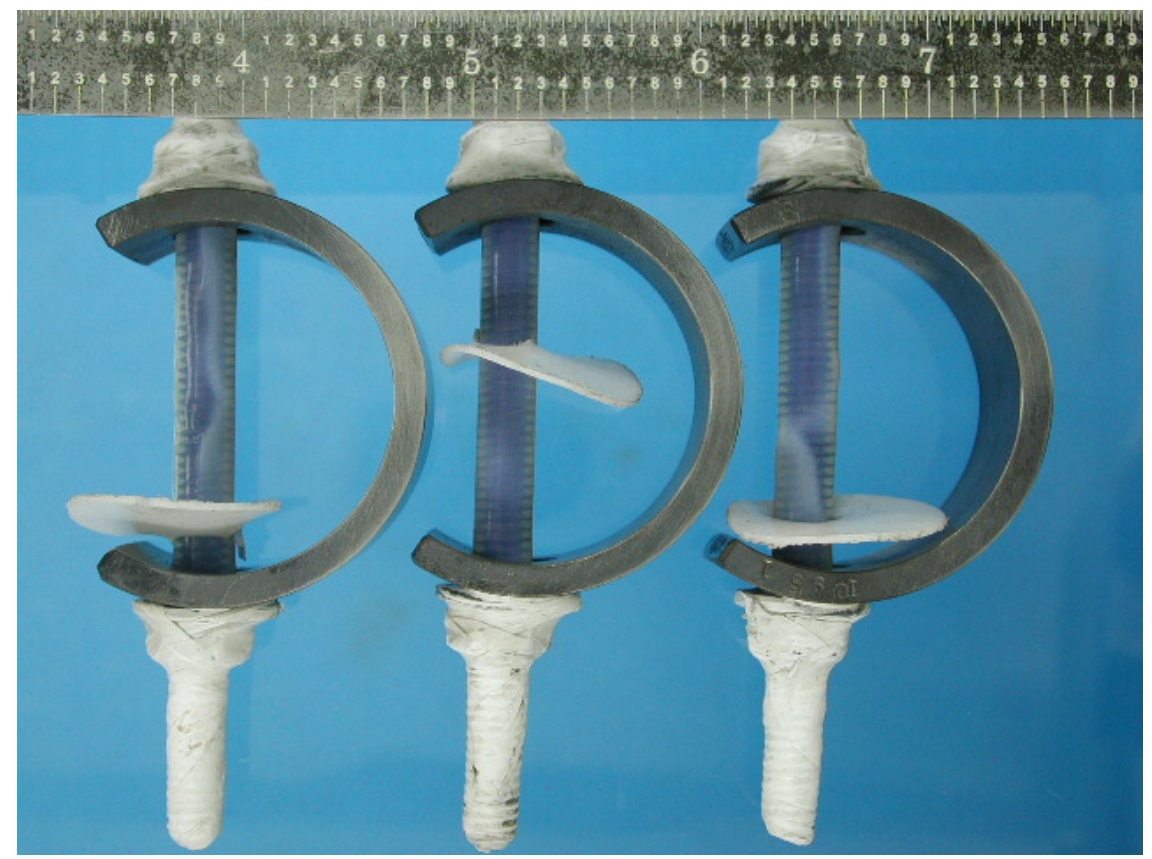

Figure 3. C-ring test specimens. Samples stressed by tension on the bolt.

The NACE MR0175 document is complex with standards that apply to specific alloys and environmental conditions. It is also a document that has evolved as the industry moved from high strength steel to stainless steel, nickel-base alloys and titanium. As such it contains some anomalies such as the unique emphasis on maximum hardness that is derived from service experience with steel. For example wrought alloy 718 is limited to Rc 40 when used in the agehardened condition regardless of the qualified yield strength of the material. This hardness restriction places some constraints on material processing. Some newer materials have been qualified for use at a slightly higher hardness.

\section{Evolution of 718 From Aircraft to Oilfield}

The first uses of 718 in the oilfield were filled with bar obtained from service centers that was intended for aircraft application. Chemistry and heat treatment likely would have been to AMS 5662 that is widely used for non-rotor materials [10]. The microstructure of this material was characterized by the presence of a significant amount of delta phase that serves to constrain grain growth, as well as a distribution of $\gamma^{\prime}+\gamma$ " designed for maximum strength. Subsequently laboratory evaluations and field failure investigations pointed the directions to chemistry, heat treatment and microstructure controls that are now expressed in API Material Specification 6A718 that covers use of 718 in oil and gas drilling and production equipment [11]. The following discussion will treat microstructure first since it has proven to be the heart of the technical solution followed by chemistry and heat treatment controls that were needed to achieve the desired microstructure.

The preceding discussion concentrated on sulfide stress corrosion cracking because it has a prominent role in the material qualification process. However, it now appears that actual field service failures are more likely associated with hydrogen embrittlement than classical stress corrosion cracking. In fact two recent field failures that played a prominent role in establishing API 6A718 were attributed to hydrogen induced fracture $[12,13]$. Copper plating is used as a lubricant on threaded joints in production pipe assemblies; the plating process may have been the 
source of the hydrogen. Another possibility is the decomposition of cesium formate brine. In both cases the undesirable combination of high level of applied stress, stress concentration at a notch, residual hydrogen and an unfavorable microstructure combined to induce the fracture.

The background for understanding of the critical interaction between hydrogen and $\delta$-phase in 718 is based on earlier work in the aerospace [14] and nuclear power industries [15]. Although the environments are quite different from those in the oil and gas industry, the evidence showed that hydrogen-cracking susceptibility of alloy 718 is directly related to the extent of $\delta$-phase coverage of the grain boundaries. Surprisingly, neither of the papers that reviewed alloy 718 in the first 718 Conference in 1989 mentioned $\delta$-phase as a criterion for performance in sour wells $[4,5]$. The operative mechanism is not well understood, but the relationship to morphology suggests that hydrogen plays a role in promoting interface de-cohesion between $\delta$-phase and the matrix. Acicular $\delta$ would be expected to be more troublesome than globular $\delta$ because it provides a linear crack path. The issue is further complicated by the fact that $\delta$-phase may be nonhomogeneous in its distribution. Improperly heat-treated alloy 718 may contain niobium-rich bands where $\delta$-phase is more concentrated and hence more prone to initiate and propagate cracking than the surrounding material. Microstructure illustrative of that revealed during examination of the Shearwater failure is shown in Figure 4b.
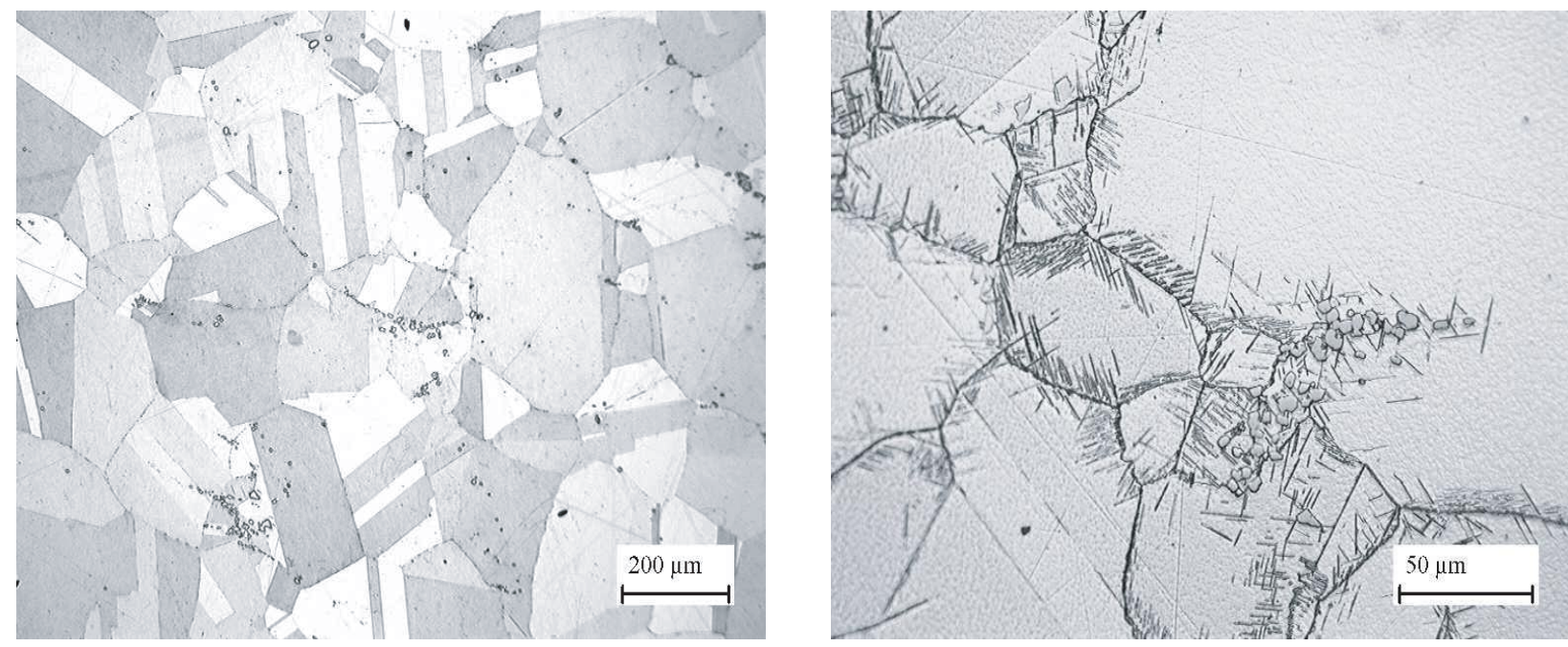

Figure 4. (a) Acceptable microstructure containing scattered carbides and isolated intergranular $\delta$-phase. (b) Unacceptable microstructure showing acicular $\delta$-phase and continuous decoration of grain boundaries.

Oilfield heat treatments historically employed a high solution treatment temperature to improve fracture toughness. Fracture toughness is important for pressure containment because designers plan for "leak before burst". The need to minimize $\delta$-phase dictated a solution treatment well above the $\delta$ solvus. This change is done at the expense of inherently coarser grain size. Table II illustrates the effect of a continuous grain boundary $\delta$-phase film on the critical ratios in an SSRT using a commonly used environment. Note that yield strength and hardness are about the same for each material condition, but the ratio indicators and toughness are adversely affected. 
Table II. Effect of $\delta$-phase on SSRT of alloy 718 [16]; Environment: $300^{\circ} \mathrm{F}\left(149^{\circ} \mathrm{C}\right), 10 \% \mathrm{NaCl}$, 358 psig $\mathrm{H}_{2} \mathrm{~S}, 200$ psig $\mathrm{CO}_{2}$, Average of 2-3 tests, (*) indicates ratio of property in environment to property in air. Heat treatments: $718 \mathrm{~S}-1875^{\circ} \mathrm{F}\left(1024^{\circ} \mathrm{C}\right)+1450^{\circ} \mathrm{F}\left(788^{\circ} \mathrm{C}\right) ; 718 \mathrm{M}-1875^{\circ} \mathrm{F}$ $\left(1024^{\circ} \mathrm{C}\right)+1725^{\circ} \mathrm{F}\left(941^{\circ} \mathrm{C}\right)+1450^{\circ} \mathrm{F}\left(788^{\circ} \mathrm{C}\right)$. Time to Failure (TTF), Charpy V-Notch $(\mathrm{CVN})$

\begin{tabular}{|c|c|c|c|c|c|c|}
\hline Material & $\begin{array}{c}\text { TTF } \\
\text { Ratio* }\end{array}$ & $\begin{array}{c}\text { \% Red.Area } \\
\text { Ratio* }\end{array}$ & $\begin{array}{c}\text { \% Elong. } \\
\text { Ratio* }\end{array}$ & $\begin{array}{c}\text { Yield Str. } \\
\text { Ksi (MPa) }\end{array}$ & $\begin{array}{c}\text { CVN Impact } \\
\text { Ft-lb (J) }\end{array}$ & $\begin{array}{c}\text { Hardness } \\
\text { Rc }\end{array}$ \\
\hline $718 \mathrm{~S}$ & 0.88 & 0.72 & 0.86 & $128.0(883)$ & $44.5(60)$ & 35.5 \\
\hline $718 \mathrm{M}$ & 0.80 & 0.61 & 0.76 & $123.3(850)$ & $27.3(37)$ & 36.7 \\
\hline
\end{tabular}

The second microstructure difference between oilfield and aerospace is the aging treatment. The conventional heat treatment was designed to produce an optimum distribution of coarse and fine precipitates via a two-step aging treatment. According to Bhavsar [6], the selection of the nominal $1450^{\circ} \mathrm{F}\left(788^{\circ} \mathrm{C}\right)$ single step aging treatment now specified in API 6A718 related more to reliability of the treatment to simultaneously achieve RC 40 hardness and minimum yield strength of $120 \mathrm{ksi}(827 \mathrm{MPa})$. In this context the under-age side of the curve is steep and with normal level of alloy inhomogeneity difficult to define. The peak of the aging curve results in hardness beyond the NACE limit. In contrast the over-aging side of the curve is less steep and more accommodating to normal variability.

The composition of oilfield alloy 718 has evolved to support the microstructure requirements and also to enhance toughness. Niobium is now restricted to $5.20 \%$ to minimize $\delta$-phase and carbon is limited to $0.045 \%$ to prevent formation of continuous grain boundary carbides during the relatively high aging temperature. Phosphorus is restricted to less than $0.010 \%$ to improve toughness. The minimum of titanium and aluminum is also increased in the oilfield grades. Individual alloy producers have identified enhanced microstructure control with even tighter limits on certain elements. As a result the oilfield and aerospace alloys have become distinct subsets within the broad definition of alloy 718. Table III compares some requirements for the two materials.

Table III. Comparison of requirements of API 6A718 and AMS 5662, a widely used specification for aircraft grades of 718 . Mechanical properties are at room temperature.

\begin{tabular}{|l|l|l|}
\hline Item & Aerospace AMS 5662 & Oilfield Spec API 6A718 \\
\hline $\begin{array}{l}\text { Solution } \\
\text { Treatment }\end{array}$ & $1725^{\circ} \mathrm{F}\left(941^{\circ} \mathrm{C}\right)$ to $1850^{\circ} \mathrm{F}\left(1010^{\circ} \mathrm{C}\right)$ & $1870^{\circ} \mathrm{F}\left(1021^{\circ} \mathrm{C}\right)$ to $1925^{\circ} \mathrm{F}\left(1052^{\circ} \mathrm{C}\right)$ \\
\hline Grain Size & ASTM 4 or 5 depending on dia. & ASTM 2 or 3 depending on dia. \\
\hline Second Phase & $\begin{array}{l}\text { No Laves, delta banding per } \\
\text { customer requirement }\end{array}$ & $\begin{array}{l}\text { No continuous GB network, No } \\
\text { acicular delta, no Laves }\end{array}$ \\
\hline Age Harden & $1325^{\circ} \mathrm{F}\left(718^{\circ} \mathrm{C}\right)+1150^{\circ} \mathrm{F}\left(621^{\circ} \mathrm{C}\right)$ & $1425^{\circ} \mathrm{F}\left(774^{\circ} \mathrm{C}\right)$ to $1475^{\circ} \mathrm{F}\left(802^{\circ} \mathrm{C}\right)$ \\
\hline Carbon & $0.080 \% \max$ & $0.045 \% \max$ \\
\hline Phosphorus & $0.015 \% \max$ & $0.010 \% \max$ \\
\hline Copper & $0.30 \% \max$ & $0.23 \% \max$ \\
\hline Niobium & $5.50 \% \max$ & $5.20 \% \max$ \\
\hline Aluminum & $0.20 \% \min$ & $0.40 \% \min$ \\
\hline Titanium & $0.65 \% \min$ & $0.80 \% \min$ \\
\hline
\end{tabular}




\begin{tabular}{|l|l|l|}
\hline Yield Strength & $150 \mathrm{ksi}(1034 \mathrm{MPa}) \mathrm{min}$ & $120 \mathrm{ksi}(827 \mathrm{MPa}) \mathrm{min}$ \\
\hline $\begin{array}{l}\text { Tensile } \\
\text { Strength }\end{array}$ & $185 \mathrm{ksi}(1276 \mathrm{MPa}) \mathrm{min}$ & $150 \mathrm{ksi}(1034 \mathrm{MPa}) \mathrm{min}$ \\
\hline Elongation & $12 \% \mathrm{~min}$ & $20 \% \mathrm{~min}$ \\
\hline Red of Area & $15 \% \mathrm{~min}$ & $25 \%-35 \%$ min depending on dia. \\
\hline Hardness & $331 \mathrm{HB} \mathrm{min}$ & $363 \mathrm{HB}$ max $(\mathrm{Rc} 40)$ \\
\hline Other & $\begin{array}{l}\text { High Temp Tensile, Notch-bar } \\
\text { Stress Rupture }\end{array}$ & $\begin{array}{l}\mathrm{CVN} \text { at }-75^{\circ} \mathrm{F}(-60 \mathrm{C}), \text { SSR per } \\
\text { customer requirement }\end{array}$ \\
\hline
\end{tabular}

\section{Manufacturing of Oilfield 718}

Manufacturing of oilfield alloy 718 is nominally similar to that of aircraft 718 but with some important distinctions. Alloy 718 ingot is primarily produced using the Vacuum Induction Melting (VIM) and Vacuum Arc Remelting (VAR) process; however, Electric Arc Furnace (EAF) - Argon-Oxygen Decarburization (AOD) processes are accepted in API 6A718 if the manufacturing process includes two (VAR) operations. VIM/ESR (Electo-Slag Remelting) and VIM/ESR/VAR are also acceptable melt combinations. Material specifications expect a "controlled process", but there is currently no counterpart of the purchaser-controlled "frozen process" system required for aircraft rotating components. The chemistry criticalities described previously have all but precluded use of aero grade material for completion components and led to distinct production circuits and scrap control for companies that produce for both applications. Open die forging is preferred for ingot conversion. Finishing of large diameter bars is generally done on an open die press while smaller diameter bars are completed on a rotary forge or reversing bar mill. Typical bar sizes range from 2 in. $(50 \mathrm{~mm})$ to $10 \mathrm{in}$. $(250 \mathrm{~mm})$ diameter, with certain well-head components requiring bars as large as 20 in. (500 mm) dia. Heavy wall tubing has been used for certain components as a means of reducing material cost. Tubing is produced by first forging a rod. The rod is peeled, cut into billets, a center hole is bored or trepanned and the billet nose is radiused. The billets are subsequently extruded to tube that may subsequently be cold drawn. At this time heavy wall tube comprises a very small portion of the alloy 718 market produced for the oilfield, but interest in this product form is increasing.

Most of the alloy 718 currently used for completion tools is purchased as "machining grade bar". It is at this point that some significant differences exist between the two grades. Machining grade bar implies that the bar manufacturer is totally responsible for the integrity, microstructure and properties of the product. In contrast for forging grade product the responsibility for these characteristics is shared between the bar manufacturer and the forger. Many oilfield applications require long lengths of bar, and are very restrictive of grinding to remove surface defects because very little stock is removed from the exterior during final machining. The finding of a rejectable Ultrasonic Test (UST) indication frequently results in loss of the entire bar because of minimum length requirements. Consequently, although the UST rejection threshold may be less restrictive than for aircraft bar, there is a comparable need for consistency and process reliability.

\section{Beyond 718}

Although alloy 718 has successfully served in the oilfield for many years, it also has some inherent limitations that drove the search for alternatives that continues to this day. Some basic issues are very high raw material cost when compared to alloy steel, and insufficient yield strength and hydrogen embrittlement resistance to serve in the most corrosive environments, 
especially those where free sulfur is present. Another problem inherent with 718 is that the manufacturing process window to meet the demanding microstructure and hardness requirements is very small and verification is difficult. Consequently, there is industry concern over reliability in commercial production. Other properties such as fatigue resistance, machinability and impact toughness of alloy 718 are sometimes mentioned as deficiencies, but have not been the basis for new development. The following discussion summarizes the development of age-hardened alloys designed to replace alloy 718 .

The earlier discussion mentioned the deficiencies of pre-existing age hardened alloys such as X750 and K-500 and alloys such as C-276 that depend on cold work for strength. The search for alternatives had the following general considerations: 1) The "Copson Curve" that defines the chloride stress corrosion cracking resistance of Fe-Ni-Cr base alloys (Min 45\% Ni) [17], 2) Hydrogen embrittlement resistance, 3) Age-hardening mechanism ( $\gamma^{\prime}, \gamma^{\prime \prime}$, other), 4)Phase stability that is heat treatable to avoid grain boundary precipitation of $\delta, \eta, \mu$, and carbides, 5) Pitting and general corrosion resistance $(\mathrm{Cr}, \mathrm{Cu}, \mathrm{Mo}, \mathrm{Nb})$. All of these considerations combined with the difficulty of definitively demonstrating performance in a wide range of corrosion environments make development of new alloys difficult and commercial acceptance slow.

Obviously a great deal of metallurgical testing and analysis was associated with the evolution of oilfield alloy 718. Some producers have identified proprietary compositional criticalities beyond those required by API 6A718. There have been further composition modification efforts, but alloy 718 is finely balanced and small changes in chemistry to avoid carbide and $\delta$ run the risk of forming Laves. One alloy 718 derivative that has been qualified for essentially the same range of environment and hardness conditions in NACE MRO175 is called PH3 (UNS N07773). This alloy has very low carbon content and hence a virtual absence of carbides. Chromium and molybdenum (higher) and niobium, aluminum and titanium (lower) are outside the definition of UNS N07718, making PH3 a distinct alloy. The alloy has been shown to have better corrosion resistance and toughness than alloy 718 [18]. To date this alloy has seen limited commercial use.

The first age-hardened nickel-base alloy to be developed specifically for the oilfield is alloy 925 (UNS N09925) [19], introduced in 1984. This $43 \% \mathrm{Ni}$ alloy was derived from the solid solution strengthened alloy 825 (UNS N08825) that is widely used for oilfield applications such as wire lines, well screens and production tubing where stress corrosion resistance is needed. Titanium was increased to provide a modest degree of age hardening from $\gamma^{\prime}$ precipitation. The nominal composition of alloy 925 and other alloys described in this section are shown in Table IV. NACE MR0175 allows alloy 925 to be used under roughly the same temperature and pressure conditions as alloy 718 , but its yield strength range is lower at $110-125 \mathrm{ksi}(758-862 \mathrm{MPa})$. This alloy is truly a lower cost alternative to alloy 718 for a wide range of well completion equipment. It also has better pitting and general corrosion resistance than 718. An additional advantage of alloy 925 is that it is niobium-free and thus cannot form $\delta$, although it is liable to the formation of carbides, $\eta$ and $\sigma$ if heat treatment is incorrectly performed [20]. Efforts to further increase the strength of alloy 925 have been unsuccessful because higher levels of titanium result in the formation of a cellular $\eta$ structure that lowers strength and toughness, and moderate additions of aluminum actually decrease ambient temperature yield strength. A lower nickel derivative of alloy 925 known as AF935 (UNS N09935) has been introduced. This alloy has a small niobium addition as well as higher molybdenum and has been qualified for use in the oilfield, but so far has not been widely used. Even lower nickel alloys are unlikely due to the increased susceptibility to stress corrosion cracking. 
Table IV. Nominal Composition (weight percent) of Age-hardened Oilfield Alloys ( $\mathrm{R}=$ residual)

\begin{tabular}{|c|c|c|c|c|c|c|c|c|}
\hline Alloy & $\mathrm{Ni}$ & $\mathrm{Cr}$ & $\mathrm{Mo}$ & $\mathrm{Nb}$ & $\mathrm{Ti}$ & $\mathrm{Al}$ & $\mathrm{Cu}$ & $\mathrm{Fe}$ \\
\hline 718 & 53.5 & 18.2 & 3.0 & 5.0 & 1.0 & 0.5 & $\mathrm{R}$ & $\mathrm{Bal}$ \\
\hline 925 & 43.5 & 20.7 & 3.0 & $\mathrm{R}$ & 2.2 & 0.2 & 1.75 & Bal \\
\hline AF935 & 36.0 & 20.2 & 3.5 & 0.5 & 2.3 & 0.2 & 1.5 & Bal \\
\hline 945 & 47.0 & 20.5 & 3.2 & 3.1 & 1.5 & 0.15 & 2.0 & Bal \\
\hline $945 \mathrm{X}$ & 53.5 & 20.5 & 3.2 & 4.0 & 1.5 & 0.10 & 2.0 & $\mathrm{Bal}$ \\
\hline 625 Plus & 61.0 & 21.0 & 8.0 & 3.4 & 1.3 & 0.20 & $\mathrm{R}$ & 7.5 \\
\hline 725 & 58.0 & 21.0 & 8.0 & 3.4 & 1.5 & 0.20 & $\mathrm{R}$ & $\mathrm{Bal}$ \\
\hline
\end{tabular}

As oil and gas drilling went to greater depths with higher temperatures and more corrosive environments, initially in Mobile Bay, it became clear that neither alloy 925 nor alloy 718 could be modified to meet expected HPHT material requirements. Nickel alloy producers, at the urging of the oil industry, then explored the path of age-hardening an inherently more corrosion resistant base composition. The favored base was alloy 625 (UNS N06625), an alloy with excellent resistance to pitting and crevice corrosion in chloride environments and acid media. Three "age-hardened 625 derivative alloys" have been qualified for oilfield use. Alloys 725 (UNS N07725) [21] and 625 Plus (UNS N07716) [22] are very similar. They rely on a titanium addition to produce a $\gamma^{\prime}+\gamma^{\prime \prime}$ aging mechanism. These alloys have been extensively characterized and documented in the literature. They have outstanding corrosion resistance and strength approaching that of alloy 718, provided that they are heat-treated carefully to avoid inter-granular $\eta$ and $\delta$ phases [16]. The third alloy, UNS N07626 that uses increased niobium for strength, would seem to be more prone to intergranular $\delta$. At present these alloys are considered the gold standard for the most severe completion applications. However, because of their higher cost, they tend to only be used as a last resort.

Another corrosion resistant alloy base C-22 (UNS N06022) was initially considered too unstable to support a $\gamma^{\prime}$ age-hardening system. However, recently a new approach that applies proprietary heat-treatments to generate strength through precipitation of a $\mathrm{Ni}_{2} \mathrm{Mo}$ phase has been reported [23]. This new alloy, called C-22HS* is rather unique in that corrosion resistance is apparently not degraded by the age hardening. This alloy has yield strength comparable to alloy 925 . Much higher strength can be obtained by a cold work and age procedure.

* Registered trademark of Haynes International Inc.

The continuing demand for versatile, economical and higher strength alloys led Special Metals to develop a new family of alloys. The objectives were lower base metal cost than alloy 718 with equivalent yield strength and resistance to formation of deleterious intergranular precipitates. The alloy design was based on lower nickel content, niobium and titanium to generate a $\gamma^{\prime}-\gamma^{\prime \prime}$ aging and increased chromium with a copper addition to improve stress corrosion cracking resistance. Alloy 945 (UNS N09945) was commercially introduced in 2008 [24]. It was designed 
for use in the 125 - $140 \mathrm{ksi}(862-965 \mathrm{MPa})$ yield strength range, however additional laboratory work showed that the strength could be increased to 140 - 165 ksi (965 - $1138 \mathrm{MPa}$ through a small increase in nickel and niobium [25]. The higher strength version is called alloy 945X. Extensive corrosion testing has been done in a range of temperatures and pressures has resulted in qualification of both alloys to NACE MR0175 / ISO 15156-3 level V and VI. The key to success of these alloys is their resistance to formation of intergranular precipitates, in particular $\delta$-phase [26]. The microstructure of annealed and aged $14 \mathrm{in}$. $(356 \mathrm{~mm}$ ) diameter bar is shown in Figure 5.
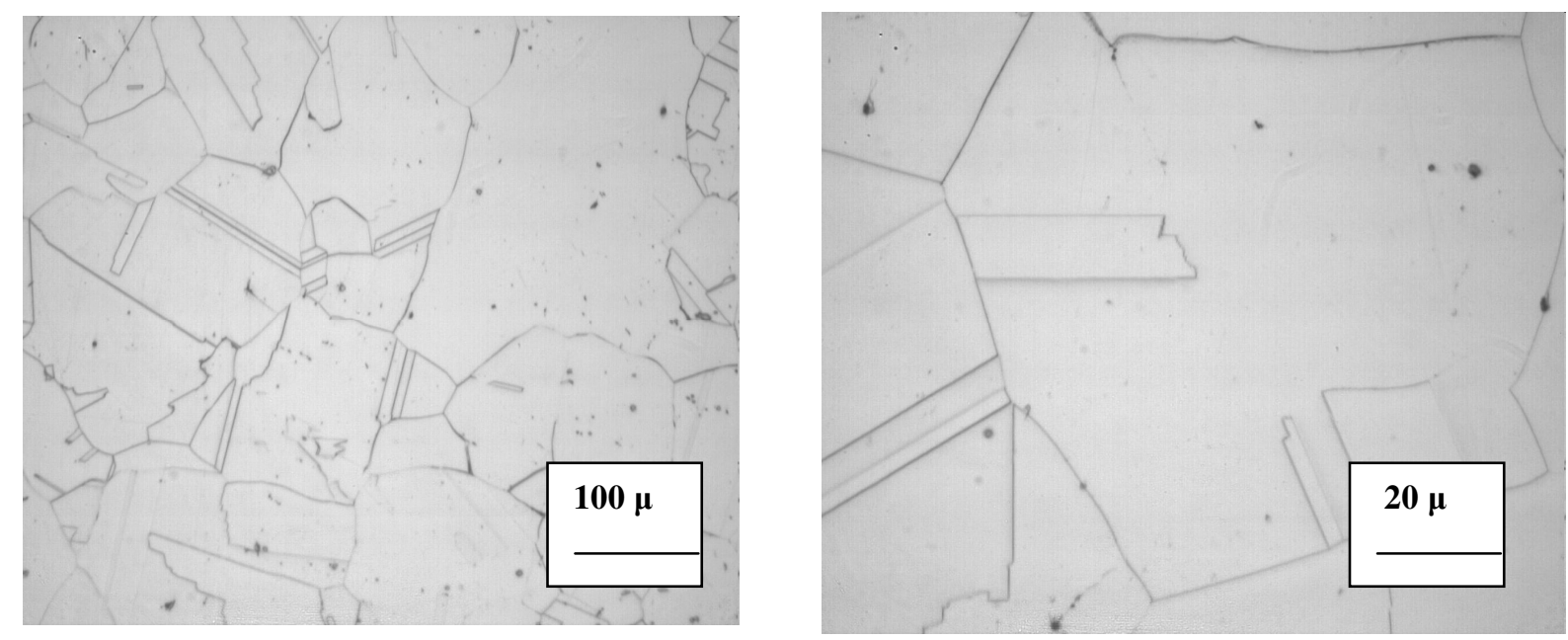

Figure 5. Longitudinal center section microstructure of solution treated and aged alloy 945. Original magnification 100 and 500X

Over the past two years the major oil production companies and down-hole equipment suppliers have conducted extensive slow strain rate and C-ring tests in a wide range of specific environments with no reported failures. The manufacturing process for this alloy is similar to that of alloys 718, 725 and 925 . Experience to date indicates that it is somewhat more forgiving than these alloys in its resistance to segregation, stress cracking and heat treatment. By virtue of its higher strength, better corrosion resistance and lower cost, alloy 945 may eventually capture a significant share of the current market for alloy 718 .

It is unlikely that we have come to the end of high strength alloy development for this industry. Figure 6 shows the current ranges for use of the various alloys. Equipment designers are already planning for the next deep-water challenges that will require yield strength approaching 200ksi. At these strength levels fracture toughness and hydrogen embrittlement will become more important criteria, and the alloys to resist them may be more specialized and expensive. 
NACE / ISO

Approved Temperature and $\mathrm{H}_{2} \mathrm{~S}$

for Alloys 718 / 725 / 925 and Alloy 945 / 945X

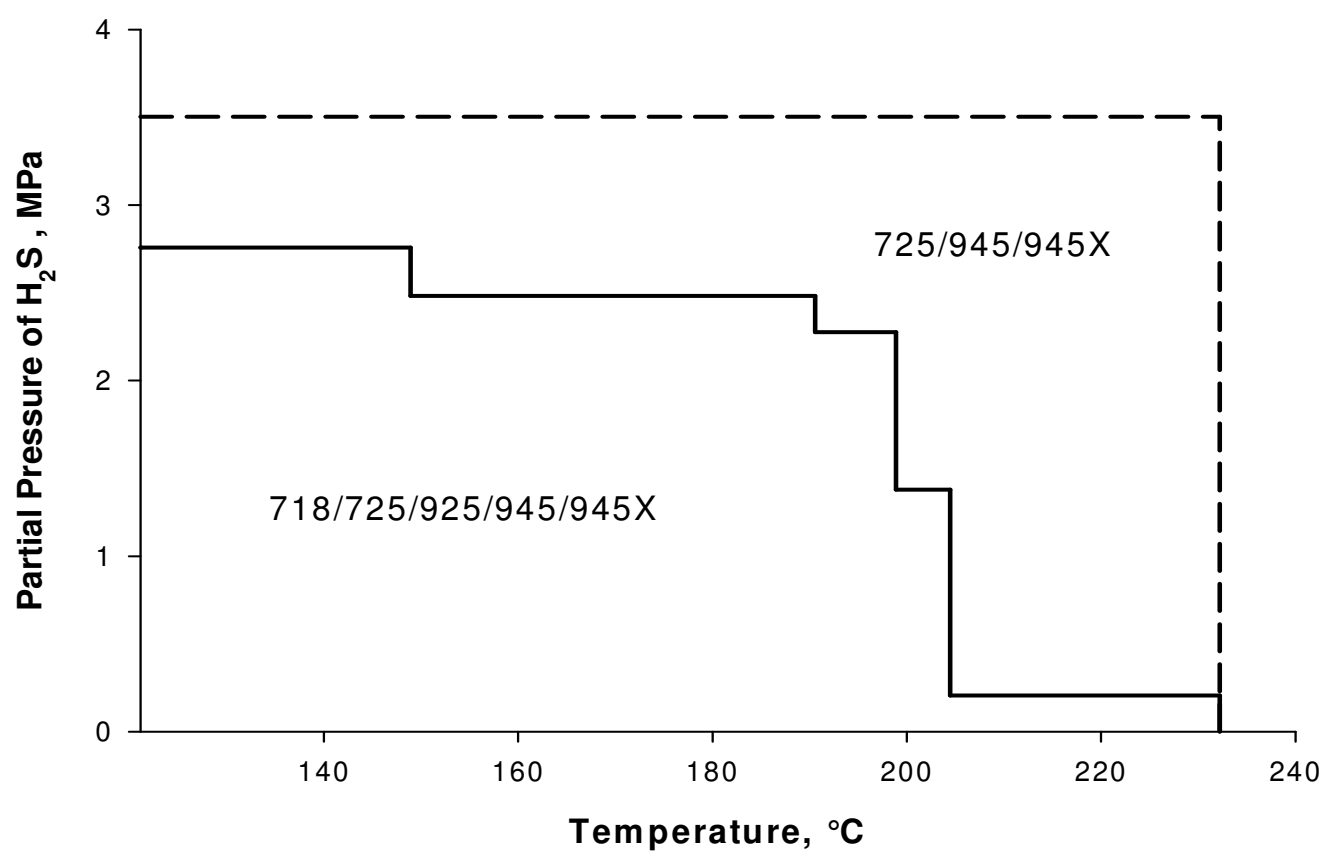

Figure 6. NACE approved ranges of temperature and $\mathrm{H}_{2} \mathrm{~S}$ pressure for selected alloys for sour gas service. [25]

\section{Summary}

Alloy 718 serves as a prime example of dual alloy use and evolution, in which a material designed for high temperature use was adopted for use as a high-strength aqueous corrosion application, and then was optimized as the service environments became more demanding. Eventually alloy 718 became sufficiently specialized that it could not be used for both applications. The alloy has served the industry well for 40 years and will be used far into the future. But 718 is no longer the sole answer for oilfield completion equipment, as requirements become increasingly severe and diversified, a number of specially designed alloys are taking a share of the oilfield application market.

\section{References}

1. H.L. Eiselstein and D.J. Tillack, "The Invention and Definition of Alloy 625", Superalloys 718, 625 and Various Derivatives, ed. E.A. Loria, TMS, 1991, pp 1-14

2. H.L. Eiselstein, “Age-hardenable Nickel Alloy”, United States Patent No. 3,046,108, July 24, 1962.

3. Inconel Alloy 718, The International Nickel Co., Inc., 1968. 
4. J. Kolts, “Alloy 718 for the Oil and Gas Industry”, Superalloy 718 - Metallurgy and Applications, ed. E.A. Loria, TMS, 1989, pp329-344.

5. O.A. Onyewuenyi, "Alloy 718 - Alloy Optimization for Applications in Oil and Gas Production”, Superalloy 718 - Metallurgy and Applications, ed. E.A. Loria, TMS, 1989, pp345362.

6. R.B. Bhavsar, A. Collins and S. Silverman, "Use of Alloy 718 and 725 in Oil and Gas Industry", Superalloys 718, 625, 706 and Various Derivitives, ed. E.A. Loria, TMS, 2001, pp 4755 .

7. International Standard, NACE MRO175/ISO 15156-3:2003.

8. NACE Standard TM0177-04, "Laboratory Testing of Metals for Resistance to Sulfide Stress Cracking and Stress Corrosion Cracking in H2S Environments"

9. R.B.Bhavsar and E.L. Hibner, "Evaluation of Corrosion Testing Techniques for Selection of Corrosion Resistant alloys for Sour Gas Service”, NACE Corrosion 96, Paper No. 59.

10. Aerospace Material Specification 5662L, Nickel Alloy Corrosion and Heat Resistant Bars, Forgings and Rings, SAE, July 2000.

11. Specification of Nickel Base Alloy 718 (UNS N07718) for Oil and Gas Drilling and Production Equipment, API Specification 6A718, March 2004.

12. S. Huizinga, et al, "Offshore Nickel Alloy Tubing Hanger and Duplex Stainless Steel Piping Failure Investigations" Corrosion 2003 Paper No 03129.

13. T. Cassagne, et al, "Understanding Field Failures of Alloy 718 Forging Materials in HP/HT Wells", EuroCorr 2008, Sept 2008.

14. R.J. Walter and W.T. Chandler, "Influence of Gaseous Hydrogen on INCONEL 718", Hydrogen in Metals, eds. I.M. Bernstein and A.W. Thompson, ASM, 1973, pp 515 - 525.

15. W.L Kimmerle, M.T.Miglin and J.L. Nelson, "Stress Corrosion Cracking of Alloy 718 in Pressurized-Water-Reactor Primary Water", Superalloy 718 Metallurgy and Applications, ed. E.A. Loria, TMS, 1989, pp 417-426.

16. S.K. Mannan, E. Hibner and B. Puckett, "Physical Metallurgy of Alloys 718, 725, 725HS, 925 for Service in Aggressive Corrosive Environments, NACE Corrosion 2003, Paper 03126.

17. H.R. Copson, "Effect of Composition on Stress Corrosion Cracking of Some Alloys Containing Nickel", Physical Metallurgy of Stress Corrosion Fracture, ed. T.N. Rhodin, Interscience, New York, 1959.

18. S. Hirano, et al, Extra Low Carbon Age-Hardenable Alloys for Tubular Application in Oil and Gas Industry, Superalloys 718, 625, 706 and various Derivitives, ed. E.A. Loria, TMS, 1994, pp 775-786. 
19. J.A. Harris et al, "The Development of a Corrosion Resistant Alloy for Sour Gas Service", NACE Corrosion 84, paper no. 216. April 2-6, 1984.

20. P. Ganesan, E.F. Clatworthy and J.A. Harris, "Development of a Time-TemperatureTransformation Diagram for Alloy 925, NACE Corrosion 87, Paper No. 286, March 1987.

21. E.L. Hibner, "A New Age-hardenable Corrosion Resistant Alloy for Deep Sour Gas Well Service”, NACE Corrosion 90, paper no. 50, April 23-27, 1990.

22. R.B Frank and T.A. DeBold. "Properties of an Age-hardenable, Corrosion-resistant Nickelbase Alloy”, NACE Corrosion 88, paper no. 75, March 21-25, 1988.

23. L.M. Pike, P.E. Manning and E.L. Hibner, A New High-Strength Corrosion-Resistant Alloy for Oil and Gas Applications, NACE Corrosion 2010, Paper No 10319.

24. S.K. Mannan and S.J. Patel, "A New High Strength Corrosion Resistant Alloy for Oil and Gas Applications, NACE Corrosion 2008, paper no. 08084, March 2008.

25. S.K. Mannan, "Alloy 945 and its Derivatives - Higher Strength Products for Oil and Gas", NACE Corrosion 2010, Paper No. 10310.

26. S.K. Mannan, “Time-Temperature-Transformation Diagram of Alloy 945", $7^{\text {th }}$ International Symposium on Superalloy 718 and Derivatives, ed. J. Groh, TMS 2010. 